\title{
LIFE HISTORIES OF THREE SERRULININI SPECIES (STYLOMMATOPHORA: CLAUSILIIDAE) FROM GEORGIA KEPT UNDER LABORATORY CONDITIONS
}

\author{
ANNA SULIKOWSKA-DROZD ${ }^{1 *}$, LEVAN MUMLADZE ${ }^{2}$ \\ ${ }^{1}$ Department of Invertebrate Zoology and Hydrobiology, University of Łódź, Poland \\ (e-mail: anna.drozd@biol.uni.lodz.pl); (i) https://orcid.org/0000-0002-2865-7130 \\ 2 Institute of Zoology, Ilia State University, Georgia \\ (e-mail: levan.mumladze@iliauni.edu.ge); (i) https://orcid.org/0000-0002-2172-6973 \\ * corresponding author
}

\begin{abstract}
The Serrulinini, a small relict group of clausiliids occurring in coastal regions of the Black and Caspian Seas and the Caucasus, are currently classified within the Phaedusinae, however paraphyletic origin of the Serrulinini is also widely debated with Pontophaedusa funiculum (Mousson) being most phylogenetically distinct from other taxa. As life history data may have taxonomical value, we conducted long-term observations in laboratory culture to assess reproductive modes, fecundity and growth pattern of three serruline species. Caspiophaedusa perlucens (O. Boettger) and Pravispira semilamellata (Mousson) produced partly calcified eggs with regular, spiral arrangement of crystals; their juveniles hatched after 17-18 days; the generation time was long and significantly exceeded one year. P. funiculum laid heavily calcified, elongated eggs. The incubation time in $P$. funiculum varied depending on the humidity, with a tendency towards short embryo-retention. The generation time in P. funiculum was one year. In all the studied species, egg calcification differed from the pattern common for other oviparous Phaedusinae which produce partly calcified eggs with homogeneous distribution of crystals. The calcite crystal distribution in the egg membranes reported here for the Serrulinini suggests some potential of these characters in phylogenetic context.
\end{abstract}

KEY WORDS: Caspiophaedusa perlucens; Pravispira semilamellata; Pontophaedusa funiculum; Phaedusinae; oviparity; embryo-retention

\section{INTRODUCTION}

Georgia, together with adjacent territories situated in the Caucasus biodiversity hotspot, is known as a centre of plant endemism with little studied and probably underestimated invertebrate richness (MUMLADZE et al. 2020). It is also an important refuge of Tertiary biota, where many hygro-thermophilous relict species found shelters during the Quaternary climate oscillations (Milne \& ABBOTT 2002). This refers, among others, to the Colchic region, which was continuously forested since the Miocene and preserved possibly one of the oldest forest ecosystems in Western Eurasia (TARKHNISHVILI et al. 2012). According to a recent survey, the Caucasus biodiversity hotspot harbours 318 land snail and slug species, $66 \%$ of them being endemic (WALther et al. 2014). Among them, 90 species were collected in a small number of forested sites in Georgia alone (POKRYSZKO et al. 2011).

Among terrestrial gastropods, unique for the region and regarded as Tertiary relicts, there are several species of Serrulinini, door-snails (Clausiliidae) included in a speciose subfamily Phaedusinae (NORDSIECK 1978, 2007). The Serrulinini tribe includes about 30 species, almost a third of them described in the 21 st century (e.g. GITTENBERGER 2000, REISCHÜTZ et al. 2016, GREGO \& SZEKERES 2017, MUMLADZE \& SZEKERES 2020). Ecological preferences in the extant Serrulinini seem to be limited to sheltered protective micro-refuges providing perma- 
nent high humidity, such as decaying wood of undisturbed forests or shallow subterranean habitats of particular cave systems. For several troglobiontic serruline species, live material has never been collected, which has impeded phylogenetic studies so far (GITTENBERGER 2000, REISCHÜTZ et al. 2016).

In the Western Palaearctic, the Phaedusinae are known from Middle Eocene to Early Pleistocene deposits of Western and Central Europe, as well as Caucasia (NORDSIECK 2015), while extant taxa occur in the Balkans, in coastal regions of the Black and Caspian Sea and Caucasia. The divergence between the Serrulinini and the Phaedusini, the more speciose tribe of the Phaedusinae occurring in East and Southeast Asia, was dated to the Late EoceneEarly Oligocene (MAMOS et al. 2021). The recent Phaedusini occur in a range of microhabitats, such as exposed rocks, stone walls, soil surface, deadwood, and many species are arboreal (e.g., MотосHIN et al. 2017, pers. obs.).

While the Phaedusinae of East and Southeast Asia are highly diversified in terms of their reproductive strategies, in the Western Palaearctic group (Serrulinini) only oviparous reproductive mode has been reported to date (SULIKOWSKA-DROZD et al. 2020, MAMOS et al. 2021). As shown in a recent phylogenetic analysis, the Caucasian Serrulinini (Pontophaedusa funiculum (Mousson, 1863) and Caspiophaedusa perlucens (O. Boettger, 1877) + Pravispira semilamellata (Mousson, 1863)) represent basal lineages within the Phaedusinae, and according to ancestral state reconstructions, the phaedusine clade (Synphroshymini excluded) evolved from an oviparous common ancestor (MAMOS et al. 2021). Studies on the life history under laboratory conditions have been published for only one serruline species, P. funiculum (PÁLL-GERGELY \& NEMETH 2008, PÁlL-GERGELY 2010), while no detailed information is known for other taxa (PÁLLGERGELY \& NEMETH 2008, MAMOS et al. 2021).

While disentangling evolutionary drivers of diversification of reproductive strategies in the Phaedusinae is in the focus of larger research projects, we herein aim to present selected data on the life histories of three members of the Serrulinini studied under laboratory conditions: $C$. perlucens, $P$. semilamellata, and P. funiculum. These species occur in mostly forested parts of the Caucasus region (Fig. 1): C. perlucens in the Elburs and Talysh Mts., the SE. slopes of the Greater Caucasus, and the N. and NE. slopes of the Lesser Caucasus; $P$. semilamellata in the western part of the Greater Caucasus and along the Black Sea coast between Sochi and Trabzon; P. funiculum in western Transcaucasia and along the Black Sea coast (SYSOEV \& SCHILEYKO 2009).

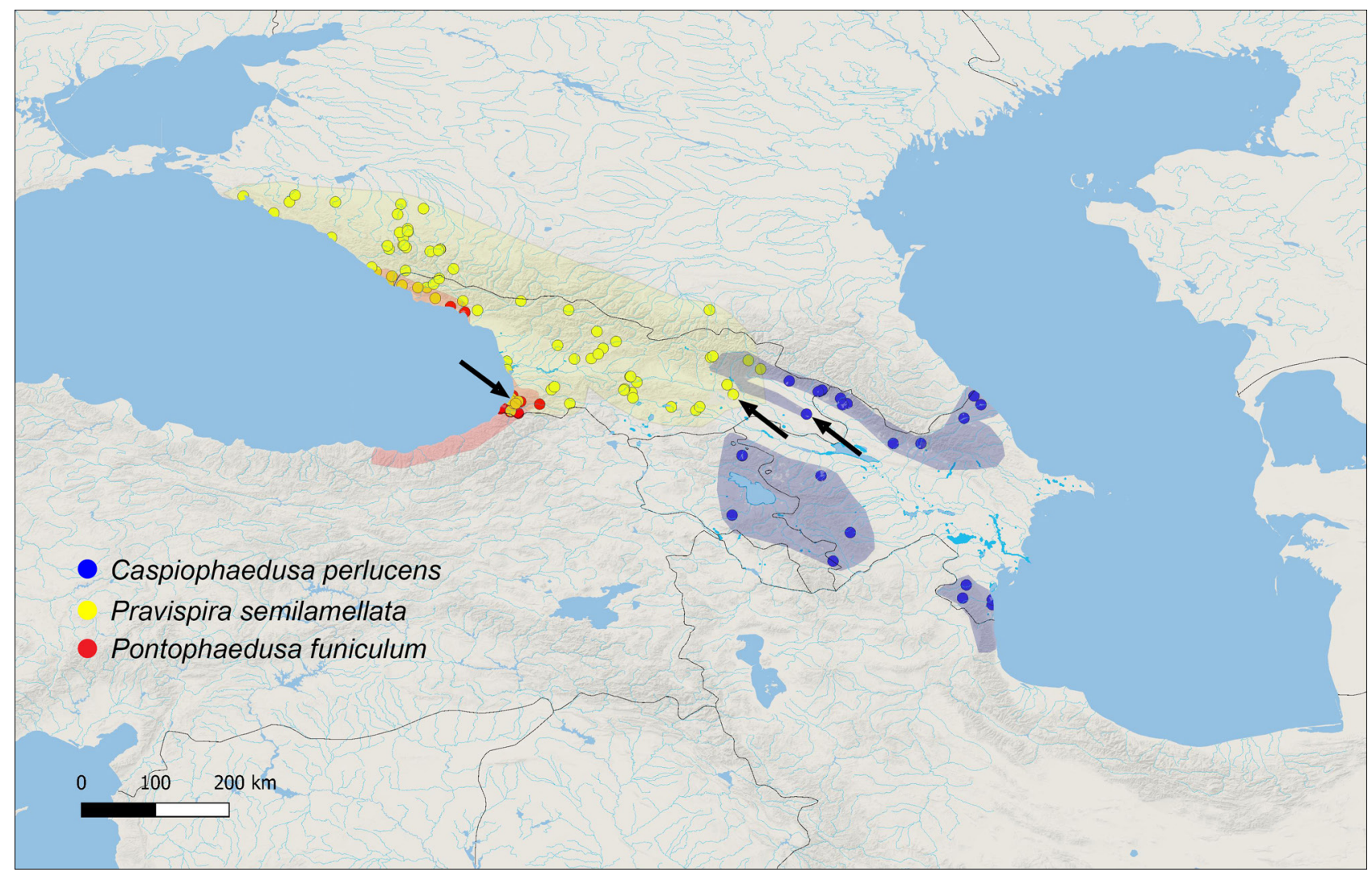

Fig. 1. Distribution of the studied species based on authors' records (unpublished) or taken from CAUCASIAN MOLLUSCAN DATABASE (2021). The map was prepared using the QGIS v. 3.16 (QGIS.org 2021). Arrows indicate the sampling sites 


\section{MATERIAL AND METHODS}

Laboratory colonies were started with individuals collected in Georgia by L. MUMLADZE (Figs 2-5): 1) C. perlucens (11 adults), Eagle Canyon near Dedoplistskaro

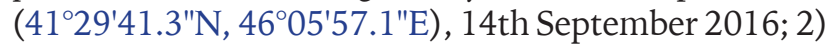
P. semilamellata (10 adults), Martkophi $\left(41^{\circ} 49^{\prime} 14.9^{\prime \prime} \mathrm{N}\right.$,

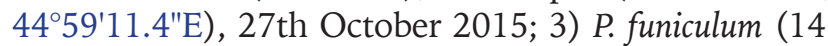
adults), Ajara, bank of the river Chaqvistskali near village Chaisubani $\left(41^{\circ} 42^{\prime} 26.6^{\prime \prime} \mathrm{N}, 41^{\circ} 46^{\prime} 33.2^{\prime \prime} \mathrm{E}\right), 30$ th October 2017.

Colonies of field-collected individuals (F0 generation) were maintained in the Department of Invertebrate Zoology and Hydrobiology, University of Łódź, Poland. Adult snails were kept in pairs in plastic boxes (volume $300 \mathrm{~cm}^{3}$ ) lined with tissue paper and supplemented with pieces of limestone as a source of calcium. The boxes were stored in a climatic chamber (POL-EKO) with natural lighting. To mimic the climate seasonality, two periods of different temperature regime were established: "summer" and "winter". From early April until the end of September the temperature fluctuated daily between $15{ }^{\circ} \mathrm{C}$ (12 hours) and $20{ }^{\circ} \mathrm{C}$ (12 hours); from October until late March the temperature was lowered to $8-12{ }^{\circ} \mathrm{C}$ (12/12 hours). The change between "summer" and "winter" season was applied within two weeks with an intermediate stage of $10-15{ }^{\circ} \mathrm{C}$ (12/12 hours). During the summer season snails were fed weekly with lettuce, cucumber and zucchini and sprayed regularly with tap water to maintain high humidity in the boxes. During the winter season fresh vegetables were not provided; the humidity was kept at a lower level (60-70\%). In the summer season, the boxes were inspected weekly for eggs; the eggs were counted and moved to Petri dishes with humid tissue paper to test the egg viability. The eggs were checked every 3-4 days for hatching. The time elapsing from egg laying to hatching (incubation time) was recorded. Juveniles (F1 generation) were kept in groups (maximum ten individuals per box) under "summer" temperatures until they reproduced for the first time; the time of attaining adult size and of the first reproduction were recorded.

Random subsets of eggs were measured under a stereomicroscope with a graticule. Then, the shape index (minor diameter/major diameter) was calculated for each egg. The egg type classification followed TOMPA (1976).

According to TOMPA (1979), the development of the embryo at the time of oviposition is important for the identification of reproductive modes in land snails. As mentioned by PÁLL-GERGELY \& NEMETH (2008), the transparent shell of $P$. funiculum allows to observe whitish eggs in the reproductive tract prior to egg-laying. Taking advantage of this situation, we ascertained the embryo development just before oviposition by dissecting several snails with such eggs (gravid individuals).

Since snails are known to cease activity and delay oviposition when experiencing adverse dry conditions, we tested the maximum duration of embryo retention by transferring five gravid individuals (F1 generation) to dry boxes. These snails were kept

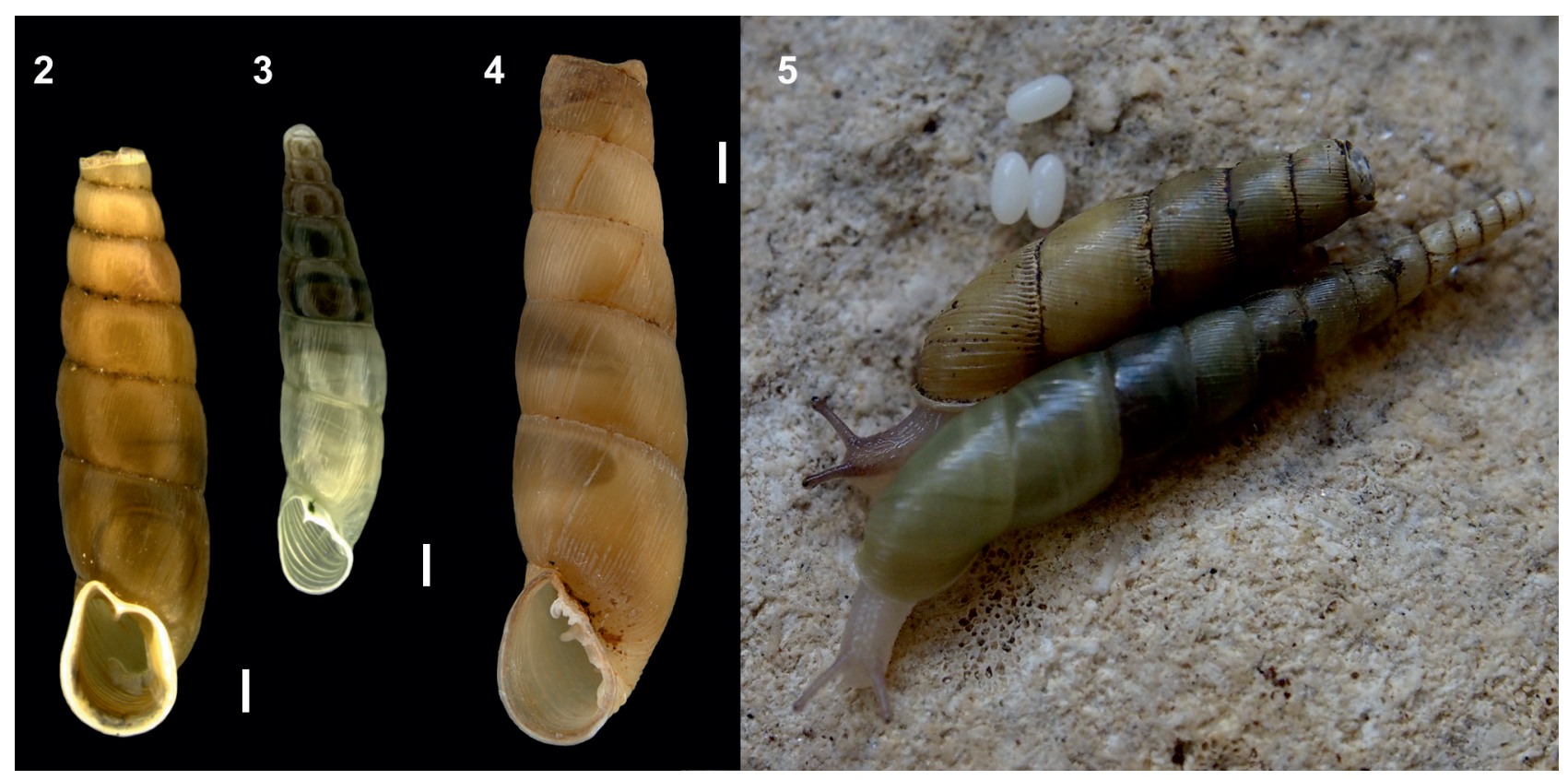

Figs 2-5. Snails from laboratory culture (F1 generation): 2 - C. perlucens decollated adult; 3 - P. semilamellata adult; 4 - P. funiculum decollated adult; 5 - P. funiculum: decollated adult (F0), subadult, and eggs. Scale bars $1 \mathrm{~mm}$ 
under dry conditions for 10, 18, and 21 days. After drought challenge, the snails sprayed with tap water and provided with fresh food were left for one day in

\section{RESULTS}

\section{LONGEVITY AND GROWTH PATTERN}

Field-collected individuals of $C$. perlucens kept in the laboratory produced their first eggs on 17 October 2016. Two adults were kept alive till the end of observation (January 2021). The last egg clutch was recorded on 14 August 2020 (1,397 days after the first reproduction in the laboratory). Their lifespan exceeded 53 months (4.5 years). Other F0 adults reproduced in 2016-2019; they were preserved for anatomical examination in July 2019. The juveniles hatched in October 2016 attained adult size in July 2017 (after 9 months). Within one month after producing apertural barriers, the snails became decollated. $\mathrm{F} 1$ individuals of $C$. perlucens produced their first eggs in January 2018. The generation time for this species was 460 days.

Field-collected individuals of $P$. semilamellata kept in the laboratory produced their first eggs on $7 \mathrm{Sep}$ tember 2016. Two adults remained alive until the end of observation (January 2021). The last egg clutch was recorded on 22 May 2020 (1,353 days after the first reproduction in the laboratory). Their lifespan exceeded 58 months (5 years). Other F0 adults reproduced in 2016 and 2017 and died between April and September 2018.

Individuals of $P$. semilamellata, hatched in the autumn of 2016, showed large discrepancies in the time needed for growth until adult size. The fastest growing F1 individuals attained adult size on the boundary of November/December 2016 (approximately 78-86 days since egg-laying) and the slowest growing individuals were still juvenile after one year. F1 individuals of $P$. semilamellata produced their first eggs in February 2018; the resulting generation time (520 days) was rather long.

Field-collected individuals of $P$. funiculum kept in the laboratory produced their first eggs on 11 April 2018. Five adults were kept alive until the end of observation (January 2021), then they were preserved separate boxes. Then, the experimental snails (and the laid eggs) were dissected to examine the embryo development.

for anatomical examination. The last egg clutch was recorded on 14 August 2020 (1,019 days after the first reproduction). Their lifespan equalled 40 months (3.3 years). Juveniles hatched in April 2018 attained adult size on the boundary of September/ October 2018 (after 5 months). Within 1-2 months after producing apertural barriers, the snails became decollated. F1 individuals of $P$. funiculum produced their first eggs in May 2019. The generation time was 390 days.

\section{EGG SIZE AND SHAPE}

The size, shape and type of egg-envelope of the eggs produced in the laboratory differed among the species (Table 1, Figs 6-11, 15). Eggs of P. semilamellata and $C$. perlucens were spherical to ovoid, those of P. funiculum were always considerably more elongated (shape index $>2$ ).

Eggs produced by P. semilamellata and C. perlucens were partly calcified, while $P$. funiculum laid eggs with heavily calcified, rigid shell (Fig. 13). The egg-envelope of $C$. perlucens exhibited a regular, spiral arrangement of calcium crystals (Fig. 7). This pattern was also discernible, but less clearly, in the eggs of $P$. semilamellata (Fig. 10).

\section{CLUTCH SIZE AND FECUNDITY}

The studied species laid eggs singly or in small clutches, i.e. several eggs adhering to one another in a particular place within the box.

Egg clutches of C. perlucens (F0 kept in pairs) consisted usually of 3-4 eggs (Table 2). During the observation period (October 2016-August 2020), ten F0 individuals produced 264 eggs. The total maximum fecundity of a pair equalled 96 eggs, recorded from 17 October 2016 till 11 July 2019. The annual fecundity ranged from 11 to 24 eggs per pair (mean 15.2 eggs, $n=5$ ), however for the years 2017 and

Table 1. Egg size and shape in Serrulinini kept in laboratory colonies

\begin{tabular}{lcccc}
\hline & & P. semilamellata & C. perlucens & P. funiculum \\
\hline no. of measurements & & 28 & 67 & 50 \\
Egg major diameter (mm) & mean (SD) & $1.56(0.15)$ & $1.96(0.18)$ & $2.51(0.14)$ \\
& min-max & $1.33-2.03$ & $1.63-2.60$ & $2.10-2.80$ \\
Egg minor diameter (mm) & mean (SD) & $1.13(0.11)$ & $1.55(0.11)$ & $1.21(0.05)$ \\
& min-max & $0.97-1.37$ & $1.30-1.83$ & $1.10-1.35$ \\
Egg shape (minor/major diameter) & mean (SD) & $0.73(0.06)$ & $0.80(0.08)$ & $0.49(0.03)$ \\
& min-max & $0.49-0.82$ & $0.56-0.98$ & $0.44-0.55$ \\
\hline
\end{tabular}



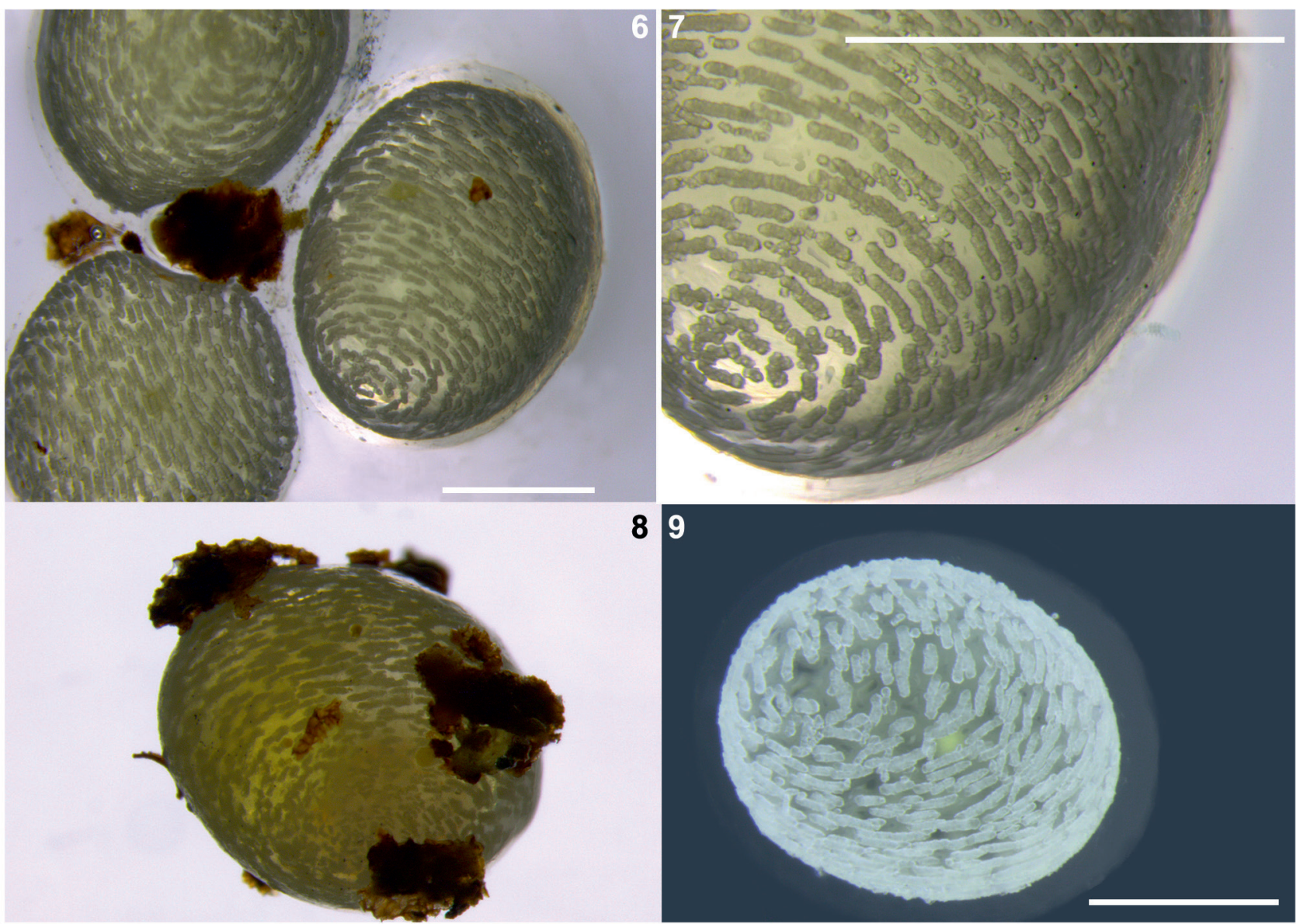

Figs 6-9. Eggs of $C$. perlucens laid in laboratory culture. Scale bars $1 \mathrm{~mm}$

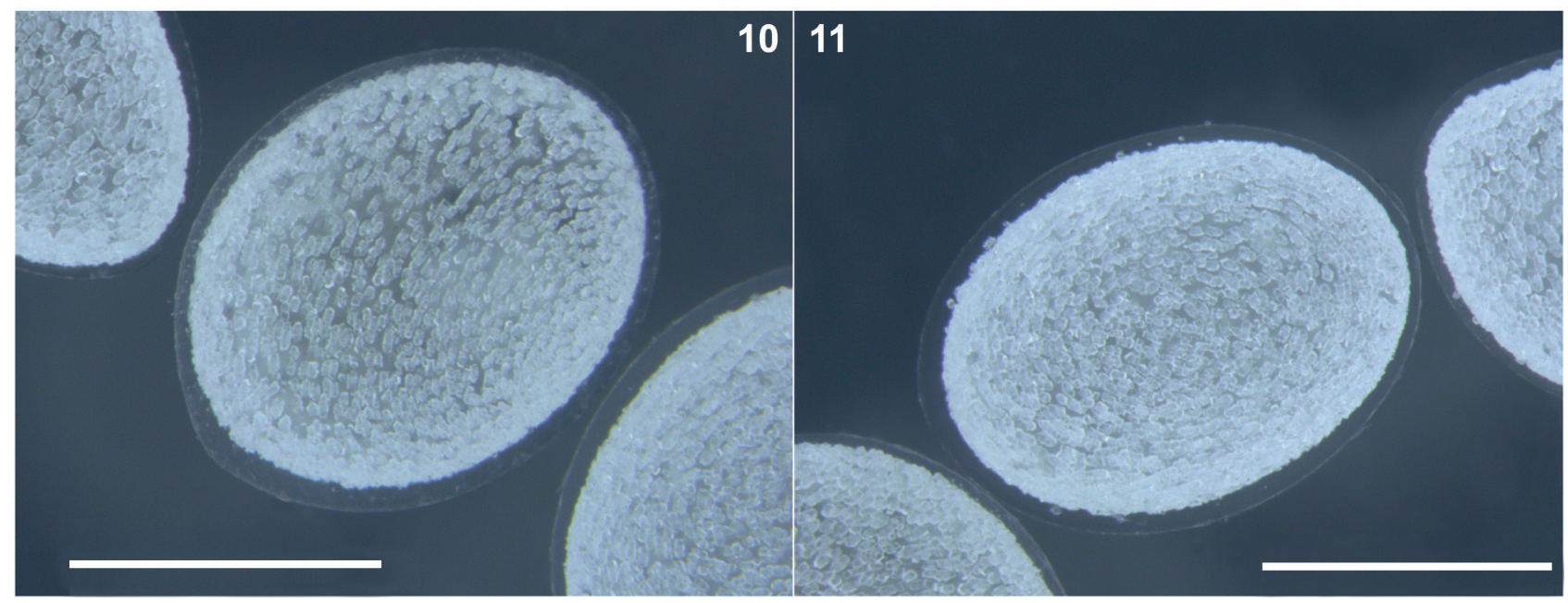

Figs 10-11. Eggs of $P$. semilamellata laid in laboratory culture. Scale bars $1 \mathrm{~mm}$

Table 2. Clutch size and egg incubation time for Serrulinini kept in laboratory colonies

\begin{tabular}{lcccc}
\hline & & P. semilamellata & C. perlucens & P. funiculum \\
\hline Number of eggs & $\mathrm{n}$ & 33 & 58 & 107 \\
& mean $(\mathrm{SD})$ & $1.8(0.80)$ & $3.1(1.19)$ & $2.82(1.03)$ \\
Incubation time & min-max & $1-4$ & $1-6$ & $1-6$ \\
& $\mathrm{n}$ & 6 & 14 & 4 \\
& mean (SD) & $17.8(4.6)$ days & $17.1(5.7)$ days & $24.0(10.4)$ days \\
\hline
\end{tabular}


2018, it was considerably higher: 11-48 eggs per pair (mean 24.2 eggs, $n=5$ ). In 2018-2020, 12 F1 individuals produced 151 eggs.

P. semilamellata (F0 kept in pairs) laid eggs usually singly or in clutches of two (Table 2). Eight F0 individuals produced 57 eggs during the observation period (September 2016-May 2020); ten F1 individuals - 45 eggs (February 2018-September 2020). The total maximum fecundity of an F0 pair equalled 32 eggs (7 September 2016-22 May 2020). In 2016, the mean annual fecundity ranged from one to 16 with only two pairs laying more than ten eggs (mean 7.75 eggs, $n=4$ ). One F0 pair did not reproduce at all, thus were excluded from the calculation.

Egg clutches of $P$. funiculum (F0 kept in pairs) consisted most often of three eggs (Table 2). 14 F0 individuals produced 671 eggs during the observation period (April 2018-August 2020), F1 individuals 349 eggs (May 2019-September 2020). In April to November 2018, the number of eggs produced per pair (F0) averaged 66 (range 25-106; n = 7). Within this period, egg laying was recorded during seven to 14 observations (weeks) for each pair.

\section{INCUBATION AND HATCHING}

The eggs of $P$. semilamellata and C. perlucens hatched on average 17-18 days after laying (Table 2). In P. funiculum, the eggs hatched on average after 24 days. The incubation time in this species was most variable, with the maximum recorded duration of 34 days. We were able to distinguish $P$. funiculum with fertilised eggs in the reproductive tract visible through the transparent shell as ready for oviposition. Dissection of such snails confirmed that the eggshell was fully calcified and inflexible prior to egg-laying (Fig. 12). The retained eggs contained embryos approximately $0.5 \mathrm{~mm}$ in diameter but without calcified embryonic shell (Figs 13-14).

When kept under experimental dry conditions, adults of $P$. funiculum with eggs already visible through the shell were inactive; moved again to a humid environment they all started crawling and feeding within 2-3 hours, yet one was found dead on the following day. Only one of the experimental adults laid eggs during the first 24 hours. These eggs contained embryos in advanced stage of development. Shelled embryos were found in the dissected individuals (Figs 16-18).

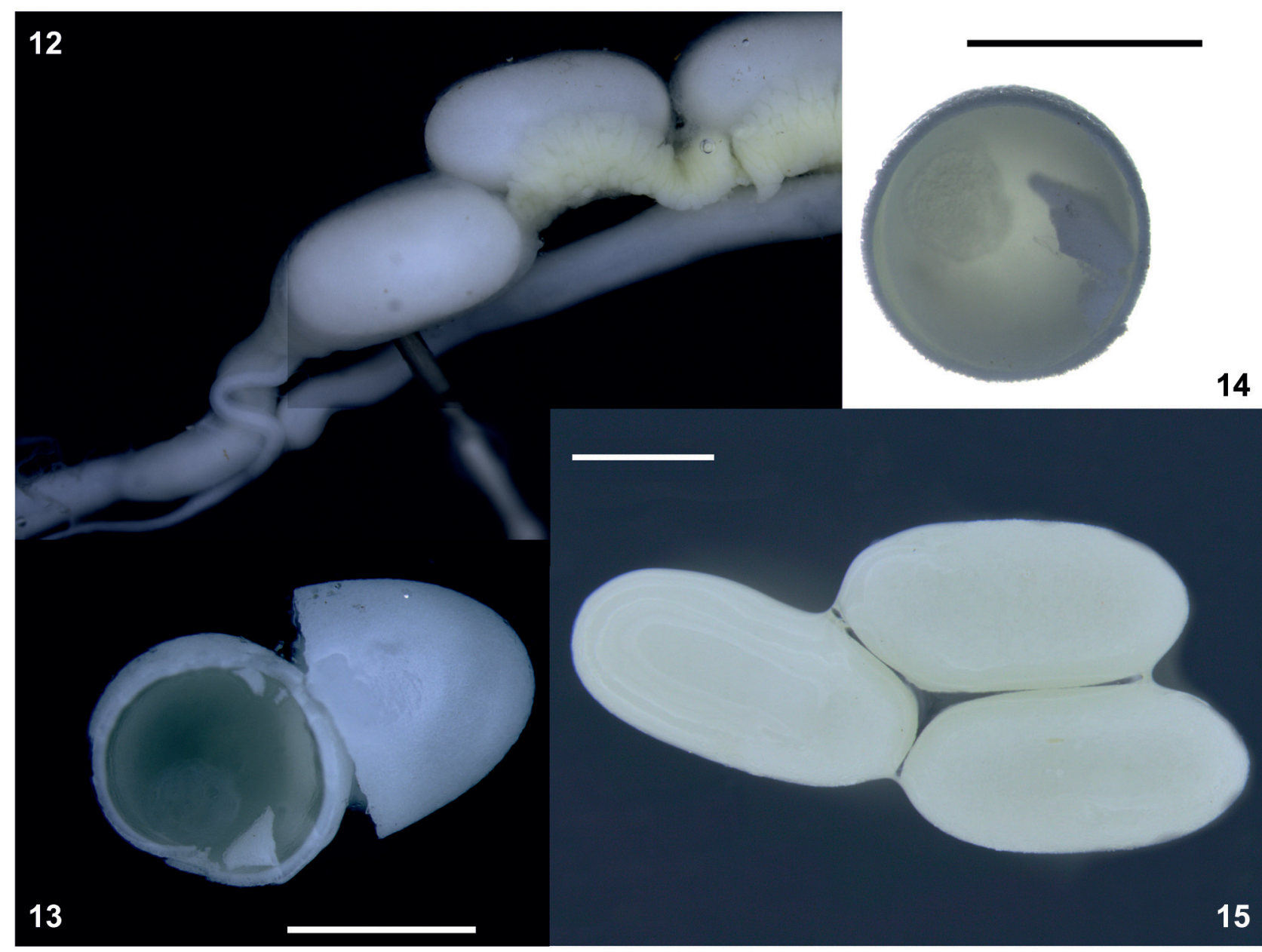

Figs 12-15. Eggs of $P$. funiculum: 12 - eggs retained in reproductive tract under high humidity conditions; 13-14-cross-section of retained eggs with visible small, shell-less embryo; 15 - egg clutch laid in laboratory culture. Scale bars $1 \mathrm{~mm}$ 


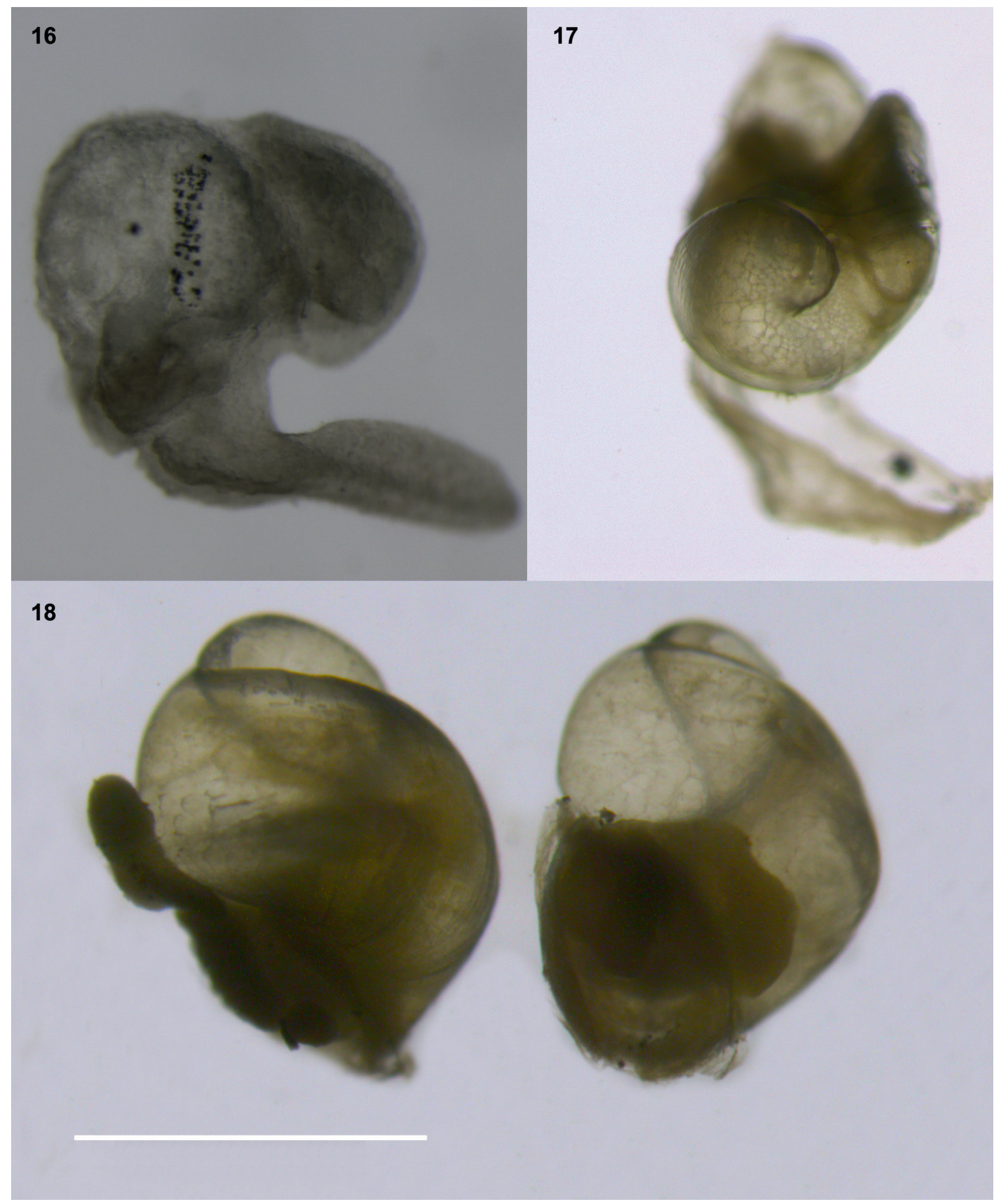

Figs 16-18. Embryos of P. funiculum: 16-17 - embryos found in eggs laid shortly after 18 day-drought; 18 - shelled embryos dissected from the adult found dead after 18 days of drought. Scale bar $1 \mathrm{~mm}$ 


\section{DISCUSSION}

As clausiliid life histories have been recently reviewed in detail (MALTZ \& SULIKOWSKA-DROZD 2008), in this contribution we discuss only selected findings which shed new light on the diversity of reproductive strategies in the Serrulinini.

Egg-laying is predominant and possibly the ancestral reproduction mode for Stylommatophora, including clausiliids (TOMPA 1979, MALTZ \& SULIKOWSKADROZD 2008). According to TOMPA (1976), in terms of degree of calcification, three types of eggs are distinguished in land snails: uncalcified, partly calcified, and heavily calcified. Calcium crystals from the egg envelope are utilised by the embryo for building its shell; newly hatched juveniles usually consume the remnants of the egg envelope. With few exceptions, most of the stylommatophoran families produce a single kind of eggs (TOMPA 1976). In the Clausiliidae, partly calcified eggs were found in all taxa studied so far, except $P$. funiculum (MALTZ \& SULIKOWSKADrozd 2008, PÁll-Gergely \& Nemeth 2008). Partly calcified eggs with randomly distributed crystals were recorded among other members of the Phaedusinae, for example Oospira vanbuensis (Bavay et Dautzenberg, 1899) (SULIKOWSKA-DROZD et al. 2018b), and in more than 20 other species from China, Japan, and Vietnam (unpublished pers. obs.). The eggs of $C$. perlucens and $P$. semilamellata are partly calcified but show a unique, spiral arrangement of crystal clusters. Clausiliid eggs are laid in collapsed state and similarly to other partly calcified eggs they absorb water from the moist soil to become spherical (TOMPA 1976). In contrast, the eggs-shells produced by $P$. funiculum are already inflexible when in uterus (PÁLL-GERGELY \& NEMETH 2008; Figs 12-15), with uniformly distributed calcite crystals forming a dense cover. Thus, the egg shell of $P$. funiculum resembles that of a small bird. A heavily calcified egg is a rather peculiar character for a snail with complex apertural barriers - during egg-laying, the eggs have to pass the narrow canal between the clausilium and the apertural lamellae. Despite the differences in calcification of the egg-shell, clausiliid eggs do not protect embryos from desiccation (pers. obs.).

Attribution of clausiliid taxa to the reproductive modes distinguished by TOMPA (1979) is not always straightforward. It has been found that a continuum of strategies occurs (different duration of embryo retention in genital tract) and only extensive studies can reveal details of developmental processes in a given species. The reproduction mode of $P$. funiculum is classified as oviparity or egg-laying, however observations in our colony and the variable incubation time of 9-20 days reported by PÁLL-GERGELY \& NEMETH (2008) suggest that egg laying not necessar- ily occurs immediately after fertilisation. According to TOMPA (1979), truly oviparous snails lay their eggs with embryos in initial stage of development, up to 24 hours after fertilisation. Under laboratory conditions, P. funiculum showed some tendency towards short embryo retention, as the retained eggs were usually visible in the parent body for a few days before egg-laying. During dissections, shelled embryos were never detected in individuals kept under high humidity conditions. However, we showed that under dry conditions $P$. funiculum could retain developing embryos for almost three weeks, during which time the embryonic shell was produced. The embryo retention in this case was induced or prolonged by adverse environmental conditions, and thus can be classified as facultative (see TOMPA 1979). The limited number of individuals in this experiment did not allow for comparison of reproductive success between individuals experiencing drought and those kept under high humidity conditions. According to our knowledge, intra-specific variation in the duration of embryo retention has never been recorded in the clausiliids, moreover $P$. funiculum provides a good model system for experimental design due to the shell transparency and the high fecundity under laboratory conditions. MAMOS et al. (2021) suggested that the ability for embryo retention may have been of importance in the evolutionary process leading to viviparity, yet the occurrence of this reproductive mode in the Phaedusinae is underestimated.

Iteroparity and longevity recorded in the studied species are typical traits of clausiliid life histories (MALTZ \& SULIKOWSKA-DROZD 2008). In terms of shell growth and maturation time, however, discrepancies between species are often observed. This is the case also in our study. F1 individuals of $C$. perlucens, $P$. semilamellata, and P. funiculum started reproducing 390-520 days after hatching, while for members of SE. Asian Phaedusinae the generation time was only 161-168 days under the same laboratory conditions (SULIKOWSKA-DROZD et al. 2018a). According to PÁlL-GERGELY \& NEMETH (2008), shell growth was completed 4-5 months after hatching in $P$. funiculum and sexual maturation occurred at about the same time. In contrast, our observations point towards a seven month delay between attaining the adult shell size and first reproduction. Delayed first reproduction was recorded in other Phaedusinae as well (SULIKOWSKA-DrOZD et al. 2018a, b). The differences in growth rate between experiments in various laboratories may be partly explained by density-dependent factors and different food provision in both cultures. It is likely that snails kept in suboptimal conditions show a slower growth rate and 
require more time to reach sexual maturity. It was shown that for development of some tree dwelling clausiliids, bark pieces (with microorganisms) taken from natural localities might be essential (MARZEC 2018).

It appears that, besides relict distribution and preference for protective habitats, the Serrulinini differ from their SE. Asian relatives, the Phaedusini, in a unique life history trait (type of egg shell). Molecular analyses show that the Serrulinini may be a paraphyletic group (UIT DE WEERD \& GITTENBERGER 2013, MAMOS et al. 2021), which was suggested already by NORDSIECK (2007). According to molecular analyses, $P$. funiculum is phylogenetically distinct from the other Serrulinini, with a divergence from its sister group at about 37.3 Ma (MAMOs et al. 2021). Life history traits, for example calcite crystal distribution in the egg membranes reported for the Serrulinini, suggest some potential of these characters in phylogenetic context. However, further accumulation of data and broader comparisons are limited by the difficult access to live individuals, especially of troglobiontic serruline taxa.

\section{ACKNOWLEDGEMENTS}

The study was supported by the National Science Centre Poland (2016/21/B/NZ8/03086). We acknowledge the technical support of EWA JANOWSKA and KAROLINA CHANIECKA (University of Lodz) with maintaining the laboratory culture of snails. The authors are also grateful for critical comments received from the reviewers of the former version of the manuscript.

\section{REFERENCES}

CAUCASIAN Molluscan Database 2021. Available online at http://hamburg.leibniz-lib.de/en/forschung/ abteilungen/malakologie/projekte/malakologie-projekt-1-kaukasus.html (accessed 28 January 2021).

GitTenberger E. 2000. Serrulininae in Greece, there may be more (Gastropoda, Pulmonata, Clausiliidae). Basteria 64: 81-87.

Grego J., SZEKeres M. 2017. Cotyorica nemethi n. gen n. sp., a remarkable Tertiary relict of the subfamily Phaedusinae (Gastropoda: Pulmonata: Clausiliidae) from northern Turkey. Ecologica Montenegrina 10: 26-30.

https://doi.org/10.37828/em.2017.10.5

MALTZ T. K., SUlikOWSKA-DrozD A. 2008. Life cycles of clausiliids of Poland - knowns and unknowns. Annales Zoologici 58: 857-880.

https://doi.org/10.3161/000345408X396783

MAmos T., Uit DE WeERd D., VON OHEImb P. V., SULIKOWSKA-DROZD A. 2021. Evolution of reproductive strategies in the species rich land snail subfamily Phaedusinae (Stylommatophora: Clausiliidae). Molecular Phylogenetics and Evolution 158: 1-8. https://doi.org/10.1016/j.ympev.2020.107060

MARZEC M. 2018. Life cycle and growth of Bulgarica cana (Held, 1836) under laboratory and natural conditions. Journal of Conchology 43: 149-166.

MiLne R. I., AвBOTT R. J. 2002. The origin and evolution of Tertiary relict floras. Advances in Botanical Research 38: 281-316. https://doi.org/10.1016/S0065-2296(02)38033-9

Motochin R., WANG M., Ueshima R. 2017. Molecular phylogeny, frequent parallel evolution and new system of Japanese clausiliids land snails (Gastropoda: Stylommatophora). Zoological Journal of the Linnean Society 181: 795-845.

https://doi.org/10.1093/zoolinnean/zlx023
MumladZe L., JAPOSHVILI B., ANDERSON E. P. 2020. Faunal biodiversity research in the Republic of Georgia: a short review of trends, gaps, and needs in the Caucasus biodiversity hotspot. Biologia 75: 1385-1397.

https://doi.org/10.2478/s11756-019-00398-6

MumladZe L., SZeKeres M. 2020. A second extant species of Pontophaedusa Lindholm, 1924 (Gastropoda, Pulmonata, Clausiliidae) from Georgia. Ruthenica 30: 149-154.

Nordsieck H. 1978. Zur Anatomie und Systematik der Clausilien, 20. Die rezenten Arten der Serrulininae und der Gattung Caspiophaedusa. Archiv für Molluskenkunde 109: 91-101.

NoRDSIECK H. 2007. Worldwide door snails (Clausiliiidae), recent and fossil. ConchBooks, Hackenheim.

NoRDSIECK H. 2015. Fossil Clausilioidea in space and time, with special emphasis on cretaceous and pre-Oligocene Cenozoic Clausiliidae (Gastropoda: Stylommatophora). Archive für Molluskenkunde 144: 83-97.

https://doi.org/10.1127/arch.moll/1869-0963/144/083097

PÁlL-Gergely B. 2010. Additional observation on the reproductive biology and development of the clausilial apparatus in Pontophaedusa funiculum (Mousson, 1856) (Gastropoda, Pulmonata, Clausiliidae, Phaedusinae). Malacologica Bohemoslovaca 9: 1-4.

PÁll-Gergely B., NeMETH L. 2008. Observations on the breeding habits, shell development, decollation, and reproductive anatomy of Pontophaedusa funiculum (Mousson 1856) (Gastropoda, Pulmonata, Clausiliidae, Phaedusinae). Malacologica Bohemoslovaca 7: 11-14.

Pokryszko B. M., Cameron R. A. D., Mumladze L., TARKHNISHVILI D. 2011. Forest snail faunas from Georgian Transcaucasia: patterns of diversity in a Pleistocene refugium. Biological Journal of the Linnean Society 102: 239-250. https://doi.org/10.1111/j.1095-8312.2010.01575.x 
QGIS.ORG 2021. QGIS Geographic Information System. QGIS Association. Available online at https://www. qgis.org/en/site/getinvolved/faq/index.html (accessed 30 March 2021).

REISCHÜTZ A., REISCHÜTZ P. L., SZEKERES M. 2016. The Clausiliidae subfamily Phaedusinae (Gastropoda, Pulmonata) in the Balkans. Nachrichtenblatt der Ersten Vorarlberger Malakologischen Gesellschaft 23: 93-117.

SULIKOWSKA-DrOZD A., CHIŻYŃSKA A., MALTZ T. K. 2018a. The reproductive strategies of clausiliid land snails from Northern Vietnam (Gastropoda: Stylommatophora). Journal of Natural History 52: 1785-1799. https://doi.org/10.1080/00222933.2018.1497211

SULIKOWSKA-DrOZD A., DUDA P., JANISZEWSKA K. 2020. Micro-CT screening of old shell collections helps to understand the distribution of viviparity in the highly diversified clausiliid clade of land snails. Scientific Reports 10: 60. https://doi.org/10.1038/s41598-019-56674-7

SULIKOWSKA-DROZD A., HIRANO T., WU S.-P., PÁLLGERGELY B. 2018b. High fecundity, rapid development and selfing ability in three species of viviparous land snails Phaedusinae (Gastropoda: Stylommatophora: Clausiliidae) from East Asia. Zoological Studies 57: 38. https://doi.org/10.6620/ZS.2018.57-38

Sysoev A., SCHILEYKo A. 2009. Land snails and slugs of Russia and adjacent countries. Pensoft, Sofia-Moscow.
TARKHNISHVILI D., GAVASHELISHVILI A., MUMLADZE L. 2012. Palaeoclimatic models help to understand current distribution of Caucasian forest species. Biological Journal of the Linnean Society 105: 231-248. https://doi.org/10.1111/j.1095-8312.2011.01788.x

TOMPA A. S. 1976. A comparative study of the ultrastructure and mineralogy of calcified land snail eggs (Pulmonata: Stylommatophora). Journal of Morphology 150: 861-888.

https://doi.org/10.1002/jmor.1051500406

TOMPA A. S. 1979. Oviparity, egg retention and ovoviviparity in Pulmonates. Journal of Molluscan Studies 45: 155-160.

https://doi.org/10.1093/oxfordjournals.mollus. a065489

Uit De Weerd D., GitTenberger E. 2013. Phylogeny of the land snail family Clausiliidae (Gastropoda: Pulmonata). Molecular Phylogenetic and Evolution 67: 201-216.

https://doi.org/10.1016/j.ympev.2013.01.011

WALTHER F., KiJashKo P. V., HARUTYUNOVA L., MuMLadze L., NEIBER M. T., HAUSDORF B. 2014. Biogeography of the land snails of the Caucasus Region. Tentacle 22: 3-5.

Received: March 30th, 2021

Revised: June 7th, 2021

Accepted: June 9th, 2021

Published on-line: August 4th, 2021 